\title{
Quality of fungicide application on trellised grapevines by a sprayer prototype
}

\author{
A. Porras-Soriano ${ }^{a *}$, A. Porras-PIEDRA ${ }^{\text {b }}$, M.L. SORIANO-MARTín ${ }^{b}$ \\ ${ }^{a}$ Delegación de Agricultura, Avenida del Ejercito 10, 19071 Guadalajara, Spain \\ ${ }^{\mathrm{b}}$ Escuela Universitaria de Ingeniería Técnica Agrícola, Ronda de Calatrava 7, Ciudad Real, Spain
}

(Accepted 10 January 2005)

\begin{abstract}
The main way of controlling grapevine pests and diseases is by spraying them with crop protection products. The aim is to deposit as many droplets as possible on potential or already established infection/infestation points. A prototype sprayer was constructed with its nozzle holder booms forming a kind of tunnel that travels over the plants. Spraying is thus performed in an enclosed space, preventing the shower of droplets from being blown away by the wind. A low evaporation rate is also achieved. Further, since the droplets have to travel only a very short distance between the nozzles and the plant surface, the coverage achieved approaches the ideal for crop protection purposes. The efficiency of the applications was determined using water-sensitive paper attached to the leaves of the plants during spraying; after spraying, these were examined using an artificial vision system. The results show that, at the maximum pressure assayed ( $0.6 \mathrm{MPa})$, the mean coverage percentage exceeded 54\% - sometimes reaching up to 79\%. This indicates that ideal product application conditions were approached, the product forming a nearly continuous film on the plant surface.
\end{abstract}

spraying / phytosanitary copper / deposit / water-sensitive paper / pixel

\section{INTRODUCTION}

Castilla-La Mancha is the most significant grapevine-growing region of Spain, with almost 300000 ha given over to the cultivation of these plants. Indeed, it is home to the largest continuous expanse of grapevines in the world. Although these vines have been traditionally cultivated on short trunks, it is now becoming more common to grow them on trellises. This new type of cultivation would be inconceivable without the use of crop protection techniques. The main method used to control vine pests and diseases is to spray crop protection products onto the surface of the plants (Porras-Piedra and Porras-Soriano, 2001). Success or failure is largely attributable to the quality of the material used and the efficiency of application (Fischer, 1986; Porras and Soriano, 1986).

Spraying should seek to deposit droplets of the chosen product in such a way that they strategically cover all potential or already established infection/infestation points. The product then has a better chance of exerting its protective or curative action. There is general consensus that the quality of an application is reflected in the number of droplets that reach each square centimetre of plant surface area. Anti-cryptogamic agents, especially contact fungicides, require so many impacts per square centimetre that the ideal would be to provide a con- tinuous, uniform, barrier-like spray of the product during its application (Soriano, 1994). To achieve this, the size of the droplets produced by the nozzles, measured as a diameter and normally expressed in microns (Himel, 1969; Menzies and Fisher, 1979; Rogers and Maki, 1986; Salyani, 1988; Salyani et al., 1987) must be taken into account.

In agreement with Evans et al. (1967) and Bouse and Carlton (1985), reducing the droplet diameter of a crop protectant (under no-drift and no-evaporation conditions) leads to greater plant coverage rates and efficiency. In practice, when a product is applied by spraying, attempts should be made to prevent the product dripping off the plants as well as drifting away in the air (Fischer, 1986; Soriano Martin, 1994; Soriano, 1997). This can be achieved by producing sprays of small, homogeneous droplets. In addition, such sprays require smaller amounts of product to cover the same surface area. However, these droplets should not be so small that they can be blown away by the wind or evaporated (Menzies and Fisher, 1979; Rogers and Maki, 1986; Salyani, 1988; Salyani et al., 1987). It was with these requirements in mind that a prototype sprayer for treating trellised grapevines was designed, constructed and tested. The aim was to use tiny droplets to achieve greater application efficiency, to reduce the actual amounts required, and to achieve the maximum effect of those delivered.

* Corresponding author: Andres.Porras@uclm.es 


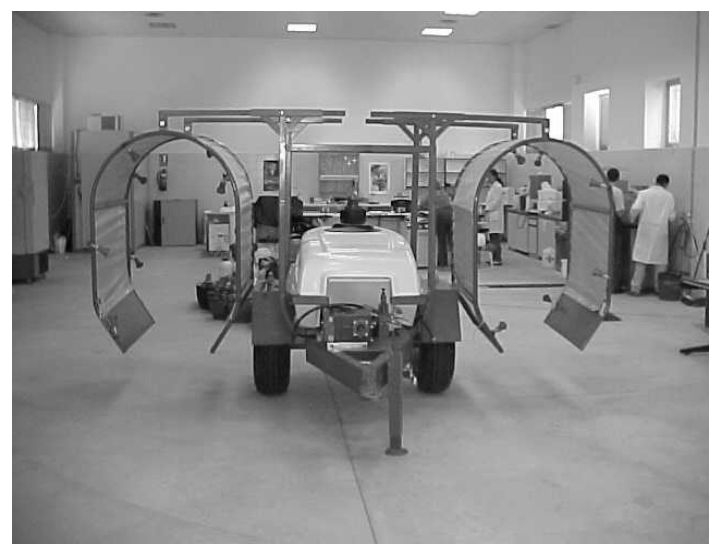

Figure 1. Prototype sprayer.

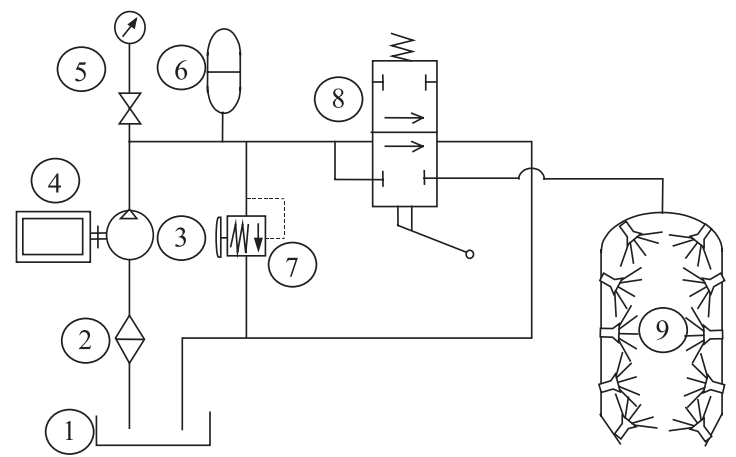

1.- Tank 2.- Filter 3.- Pump 4.- Engine 5.- Manometer 6.- Accumulator 7.- Pressure regulator 8.- Distributor 9.- Spraying tunnel

Figure 2. Hydraulic elements of the prototype sprayer.

\section{MATERIALS AND METHODS}

Figure 1 shows the prototype sprayer. The booms are archshaped, forming tunnels on either side of the machine that ride over the rows of crop. These tunnels are covered with a plasticised canvas, providing a closed chamber that prevents drifting. The tunnels are secured to the main structure and can be adapted to different crops. The arches of each tunnel support the spraying nozzles. To further prevent drifting, these nozzles are located so that the droplets are sprayed towards the inside of each tunnel. The arches are in fact formed by the piping through which the product moves towards the nozzles.

Figure 2 shows the sprayer's hydrostatic circuit. The design is close to that recommended by the I.S.O.

Full flow swirl-type spray nozzles were employed in this prototype. The flow formed is a cone whose angle can be manually changed from $20^{\circ}$ to $80^{\circ}$. To improve the uniformity of distribution, the nozzles were constructed to allow all necessary orientations to be achieved. Five nozzles line the front and back part of the tunnels.
The prototype was tested at three different working pressures $(0.1,0.3$ and $0.6 \mathrm{MPa})$ in a 12-ha trellised vineyard planted in June, 2000. Syrah, Cabernet, Sauvignon, Petit Verdot and Tempranillo varieties were cultivated in equal proportions. The vines were planted $1.5 \mathrm{~m}$ apart in rows, with $3 \mathrm{~m}$ between these rows. The droplets reached their impact points without the use of an auxiliary fluid.

Before the product was applied, 36 water- and oil-sensitive paper strips $(76 \times 26 \mathrm{~mm})$ (TeeJet; marketed by Spraying Systems Co. Wheaton IL, USA) were fixed with clips to either side of the outer leaves of plants in every row. These strips turn from yellow to blue when they come into contact with water or oil. Papers were placed on the lower, middle and upper parts of every other plant in each row. This was performed for each pressure assay.

To determine the percentage of paper surface struck by the sprayed droplets, a HP Vectra computer (running Aldus Photo Styler and in-house Turbo-basic software) and a HP Scanjet 6300 scanner were used. When dry, the papers were placed in the scanner to be digitised. The images were memorised as BMP files $(640 \times 480$ pixels; resolution at 100 pixels per inch $)$. The in-house program was then used to analyse them. This program consists of an artificial vision method (Guyer and Miles, 1985; Kranzler et al., 1985) that inspects the digitised images and determines the percentage of the leaf surface covered by the droplets (represented by blue pixels).

The fungicide used was Cuprevel (Kenogard S.A., Barcelona, Spain). This is a combination of broad spectrum fungicides with copper oxychloride ( $22 \%$ by weight), mancozeb (17.5\% by weight) and wettable powder $(60.5 \%)$. The dose used was $10 \mathrm{~g} \mathrm{~L}^{-1}$ water. The application rate was $20 \mathrm{~cm}^{3} / \mathrm{m}^{2}$.

In order to apply the same amount of product per hectare at the three assay pressures, the flow curve for the spraying booms $\left(\mathrm{cm}^{3} / \mathrm{s}\right)$ against the working pressure of the nozzles was plotted (flow-pressure curve). For this, the least squares of the data obtained in laboratory assays were used. To obtain this curve, the flow of the jets from the spraying nozzles working at 0.1 , 0.3, 0.6, 0.9, 1.2 and 1.5 MPa were measured, and the data fitted to a potential function using the Curve Expert 1.3 program.

Once the flow-pressure curve for the prototype was obtained, the apparatus (with 3/4 of its tank filled with water) was hitched to a 60-Kw nominal power tractor (Deutz Far DX model), equipped with a four-combination reducer, neutral and four forward change (1st, 2nd, 3rd and 4th) gearbox. This provided 12 forward gears as well as 4 reverse gears. The machinery travelled around the lanes of the test vineyard to obtain the equations of the straight lines representing its displacement velocity in terms of engine rotation speed. This test was performed twice. The vehicle's tachometer was used to measure the rotation speed of the tractor engine during the assay, after previously verifying its performance using a digital reflection tachometer (Sony model DT5350-C). This provides measurements with only a $2 \%$ error.

Data were analysed by ANOVA followed by a multiple range test. All calculations were performed using T StatGraphics Plus 2.1 software. 
Table I. $\mathrm{K}_{\mathrm{i}}$ values.

\begin{tabular}{lccc}
\hline \multicolumn{3}{c}{$\mathrm{K}_{\mathrm{i}}$ values } \\
\hline Velocity & Low gear & Medium gear & High gear \\
\hline First & 2.61 & 6.27 & 11.65 \\
Second & 4.11 & $9, .7$ & 17.93 \\
Third & 5.72 & 13.50 & 25.12 \\
Fourth & 8.44 & 19.71 & 36.45 \\
\hline
\end{tabular}

Table II. Work pressures and displacement speeds.

\begin{tabular}{lc}
\hline $\begin{array}{l}\text { Pressures } \\
(\mathrm{MPa})\end{array}$ & $\begin{array}{c}\text { Displacement speed } \\
(\mathrm{m} / \mathrm{s})\end{array}$ \\
\hline 0.1 & 1.19 \\
0.3 & 1.84 \\
0.6 & 2.43 \\
\hline
\end{tabular}

\section{RESULTS}

The flow-pressure equation obtained was:

$$
\mathrm{Q}=357.32 \times \mathrm{P}^{0.3961}
$$

where:

$$
\begin{aligned}
& \mathrm{Q}=\text { flow from spraying booms in } \mathrm{cm}^{3} / \mathrm{s} \\
& \mathrm{P}=\text { working pressure of nozzles in } \mathrm{MPa} \text {. }
\end{aligned}
$$

It can be seen that as the working pressure rises, so does the nozzle flow. Thus, higher tractor-prototype speeds are required to maintain the planned flow.

The tractor displacement velocity, expressed in $\mathrm{m} / \mathrm{s}$, depends on the engine rotation speed (expressed in r.p.m.), and it is obtained as follows:

$$
\mathrm{V}=10^{-4} \cdot \mathrm{K}_{\mathrm{i}} \cdot \mathrm{n}
$$

where $\mathrm{K}_{\mathrm{i}}$ is the slope of the straight line corresponding to each gear. This equation shows that for each tractor gear, the displacement speed increases linearly with the engine rotation regime.

Table I shows the $K_{i}$ values for the different tractor gearbox combinations obtained after the assays of the prototype had been performed.

Table II shows the displacement speeds necessary for supplying the established dose of product $\left(\mathrm{cm}^{3} / \mathrm{m}^{2}\right)$, based on the flow-pressure and displacement speed-engine rotation curves.

Table III shows the selected gears and engine rotation speeds used once the displacement speeds required to supply the dose of $20 \mathrm{~cm}^{3} / \mathrm{m}^{2}$ had been calculated.

Tables IV and $\mathrm{V}$ give the means, minima, maxima and standard deviations obtained in the paper strip tests (expressed as percentage area covered). Great variation was recorded for the different pressures tested; the percentage area of the papers covered increased with spraying pressure. In addition, the upper side of the leaves was sprayed more efficiently than the lower sides.
Table III. Summary of assay characteristics.

\begin{tabular}{lccc}
\hline $\begin{array}{l}\text { Pressures } \\
(\mathrm{MPa})\end{array}$ & $\begin{array}{c}\text { Speed of tractor } \\
(\mathrm{m} / \mathrm{s})\end{array}$ & $\begin{array}{c}\text { Engine rotation } \\
\text { speed (R.P.M.) }\end{array}$ & Gear \\
\hline 0.1 & 1.19 & 1233 & 2nd medium \\
0.3 & 1.84 & 1369 & 3rd medium \\
0.6 & 2.43 & 1356 & 2nd high \\
\hline
\end{tabular}

Table IV. Coverage (\%) of water-sensitive papers (means, minima, maxima and standard deviations). Values in columns followed by different letters indicate significant differences $(P \unlhd 0.05)$.

\begin{tabular}{lcccc}
\hline $\begin{array}{l}\text { Pressures } \\
(\mathrm{MPa})\end{array}$ & Lower side & Minimum & Maximum & Stand. dev. \\
\hline 0.1 & $5.795 \mathrm{a}$ & 3.69 & 9.55 & 1.551 \\
0.3 & $9.867 \mathrm{ab}$ & 6.31 & 14.76 & 2.399 \\
0.6 & $15.119 \mathrm{~b}$ & 8.31 & 22.39 & 4.589 \\
\hline
\end{tabular}

Table V. Coverage (\%) of water-sensitive papers (means, minima, maxima and standard deviations). Values in columns followed by different letters indicate significant differences $(P \unlhd 0.05)$.

\begin{tabular}{lcccc}
\hline $\begin{array}{l}\text { Pressures } \\
(\mathrm{MPa})\end{array}$ & Upper side & Minimum & Maximum & Stand. dev. \\
\hline 0.1 & $21.599 \mathrm{a}$ & 7.88 & 29.38 & 5.878 \\
0.3 & $36.071 \mathrm{~b}$ & 15.86 & 78.95 & 14.944 \\
0.6 & $54.297 \mathrm{c}$ & 22.41 & 79.53 & 18.120 \\
\hline
\end{tabular}

\section{DISCUSSION}

The great variation in the percentage of the water-sensitive paper covered, and the influence of spraying pressure on this coverage, may be due, in part, to the high density of leaves on these plants (Travis et al., 1987). Further, the great variability in vine leaf orientation (Tu et al., 1988) with respect to the droplets sprayed from the nozzles means some leaves form protective screens over others. This clearly hinders the deposition of droplets on all leaves. In addition, Himel (1969), Menzies and Fischer (1979), Rogers and Maki (1986), Salyani (1988) and Salyani et al. (1987) indicate that, at higher pressures, the diameter of the droplets produced by the nozzles is smaller, which allows greater coverage of the foliar surface. It must be pointed out as a success of the prototype that, at $0.6 \mathrm{MPa}$, the percentage area covered was up to $79 \%$. The apparatus appears to produce an almost continuous film on the leaf surface and approaches the ideal for the application of this kind of product.

In agreement with Pielou et al. (1962), better coverage of the upper side of the leaves was achieved. This is to be expected: getting the droplets to the lower side of the leaf is much more difficult since grapevines always present the upper side to the light.

The coverage obtained on both sides of the leaves increased with nozzle pressure. Significant differences $(P=0.05)$ were seen in the coverage achieved at the three different pressures. This was a design objective. Since the plants are sprayed inside a closed tunnel, the coverage improves with increasing spraying pressure because the droplets formed are smaller and form 
a cloud. Under these conditions of reduced drift, they are efficiently deposited on the leaves.

In conclusion, this prototype, built to apply crop protection products to trellised grapevines, worked perfectly in this type of vineyard and provided high leaf coverages. Although the ideal situation - a fully continuous film of product on all leaf surfaces - was not achieved, a coverage of over 54\% (sometimes as high as $79 \%$ ) was achieved at the maximum pressure. The efficiency of the prototype therefore approaches the ideal.

With respect to the surface covered, significant differences were seen at the three pressures assayed. As the working pressure increased (producing smaller droplets) so too did the percentage of plant surface covered by the droplets, both on the upper and the lower sides of the leaves.

Acknowledgements: The authors wish to thank Professor Francisco Montes Tubio and Mr. Clodoaldo Cano Arévalo for their help during the building of the prototype, and the Domecq company for funding both its manufacture and the assays performed.

\section{REFERENCES}

Bouse L.F., Carlton, J.B. (1985) Factors affecting size distributions of vegetable oil spray droplets, Trans. ASAE 28, 1068-1073.

Evans E., Cox J., Taylor J.W.H., Runham R.L. (1967) Some observations on size and biological activity of spray deposits produced by various formulations of copper oxychloride, Ann. Appl. Biol. 58, 131-144.

Fischer J.K. (1986) Nouvelles recherches pour améliorer la pulverisation, Rev. Suisse Vitic. Hortic., 18.

Guyer D.E., Miles G.E. (1985) Potential for computer vision as a spray controller, Agri-Mation 1, 156-164.

Himel C. (1969) The fluorescent particle spray droplet tracer method, J. Econ. Entomol. 6, 912-916.
Himel C.H. (1969) The optimum size for insecticide spray droplets, J. Econ. Entomol. 62, 919-925.

Kranzler G.A., Devoe D.R., Down H.N., Stone M.L. (1985) Computer vision for evaluation of agricultural chemical application, AgriMation 1, 136-141.

Menzies D.R., Fisher R.W. (1979) The effect of droplet volume median diameter and application rate per hectare on coverage uniformity in apple trees, Can. Agr. Eng. 21, 15-18.

Pielou D.P., Williams K., Brinton F.E. (1962) Differences in the deposit and persistence on the upper and lower surface of leaves, Nature $195,256-257$

Porras Piedra A., Soriano Martín M.L. (1986) Máquinas pulverizadoras de tracción mecánica. Principios y características, Dirección General De Investigación y Extensión Agrarias. Junta de Andalucía, Sevilla, Spain.

Porras Piedra A., Porras Soriano A. (2001) Tecnología de la pulverización de productos fitosanitarios, Servicio de publicaciones de la Universidad de Córdoba, Spain.

Rogers R.B., Maki R. (1986) The effect of drop size on spray deposit efficiency, ASAE Paper No. 86-1508, 7 p.

Salyani M. (1988) Droplet size effect on spray deposit efficiency of citrus leaves, Trans. ASAE 31, 1680-1684.

Salyani M., Hedden S.L., Edwards G.J. (1987) Deposit efficiency of different droplet sizes for citrus spraying, Trans. ASAE 30, 15951599.

Soriano Martín M.L. (1994) Calidad de aplicación y persistencia de fungicidas cúpricos en olivo (Olea europaea) (Tesis doctoral), Servicio de Publicaciones e Intercambio Científico (Universidad de Santiago de Compostela), Santiago de Compostela, Spain.

Soriano M.L. (1997) Aplicación foliar de productos fitosanitarios (El cultivo del olivo), Mundi-Prensa, Madrid, Spain.

Travis J.W., Skroch W.A., Sutton T.B. (1987) Effects of travel speed, application volume, and nozzle arrangement on deposit and distribution of pesticides in apples trees, Plant Dis. 71, 606-612.

Tu Y.Q., Lin Z.M., Zhang J.J. (1988) The effect of leaf shape on deposit of spray droplets in rice, Crop Prot. 5, 3-7. 